\title{
They're not just using Web sites: A citation study of 116 student papers
}

A fear often expressed by today's academic librarians is that students at their institutions are using Web sites at the expense of more reputable resources, such as books and journals. In order to study just how true this perception might be at the College of Mount St. Joseph, a private college with an enrollment of 2,500 , I requested faculty to forward to the bibliographies of student papers. Six faculty members, each from a different discipline, responded, leaving me to compile statistics from a total of 116 papers. The results from this sample are discussed below.

As Table 1 indicates, the papers yielded 854 citations. A look at the totals reveals that

\begin{tabular}{|c|c|c|c|c|}
\hline Discipline & Citations & Articles & Books & Web Sites \\
\hline Sociology & 260 & $20 \%$ & $36 \%$ & $44 \%$ \\
\hline Physical Therapy & 234 & $82 \%$ & $18 \%$ & $0 \%$ \\
\hline Religion & 149 & $20 \%$ & $54 \%$ & $26 \%$ \\
\hline Humanities & 83 & $11 \%$ & $42 \%$ & $47 \%$ \\
\hline Nursing & 66 & $41 \%$ & $56 \%$ & $3 \%$ \\
\hline Chemistry & 62 & $48 \%$ & $27 \%$ & $24 \%$ \\
\hline Totals & 854 & $41 \%$ & $35 \%$ & $24 \%$ \\
\hline
\end{tabular}

submitted. The only upper-level courses were those from humanities and religion. The physical therapy and nursing courses were mid-level, and those from sociology and chemistry were lower level. Resource requirements outlined by instructors varied from course to course and had a more profound effect.

The physical therapy instructor did not allow the use of any Web sites; the nursing instructor required that students obtain her permission to use them as sources for their papers. As the numbers in Table 1 indicate, the instructors in the other disciplines adopted a more lenient stance.

Certainly the addition of Web sites has influ-

the traditional research sources, articles and books, remain those most often used. Together they made up 76 percent of the citations, Web sites accounting for the remaining 24 percent. Exceptions to this pattern are the sociology and humanities papers, for which Web sites were used more than any other resource.

No consistent pattern emerged from an examination of course levels for the papers

ries of steps, including digitizing the microfilm, converting more than 400,000 page images to text, correcting any errors resulting from the optical character recognition software, and creating the search feature.

Works currently available online are from authors such as Bret Harte, Nathaniel Hawthorne, and Washington Irving.

Indiana University's Digital Library Program is the project host for Wright American Fiction, which is freely available on the Web at http://www.letrs.indiana.edu/web/w/ wright2/. enced how students conduct research. If my institution is any true indicator, faculty acceptance of Web sites as legitimate resources is by no means universal, but seems to have become valid for many. Students have embraced Web sites and seem to use them with books and articles. For the time being, however, the more traditional resources remain in the ascendancy.-Paul O. Jenkins, College of Mount St.Joseph, Paul Jenkins@mail.msjed

\section{New Web site profiles Sanford Berman Papers at UIUC}

The personal papers of prominent library cataloger and activist Sanford Berman are now profiled in a Web site at the University of Illinois Library at Urbana-Champaign (UIUC). Maintained by the University Archives, the Web site highlights the career of Berman, former cataloger at the Southdale Hennepin County Library in Minnesota and best known for successfully challeng ing the outdated terminology of widely accepted library catalog subject headings.

The Berman Papers are part of the AIA Archives held by the UIUC library and pro- 